\title{
Vesiculation kinetics of variably crystalline rhyolites
}

\author{
S. KOLZENBURG ${ }^{1,2,3}$ K. Berlo ${ }^{2}$, D.B.DingWelL ${ }^{1}$ \\ ${ }^{1}$ Department of Earth and Environmental Sciences, Ludwig- \\ Maximilians-University, Munich, Theresienstraße. 41 \\ 80333, Germany \\ ${ }^{2}$ Department of Earth and Planetary Sciences, McGill \\ University, 3450 University Street, H3A 0E8 Montreal, \\ Quebec, Canada \\ ${ }^{3}$ Department of Geology, University at Buffalo, 126 Cooke \\ Hall, 14260 Buffalo, New York
}

Bubble nucleation and growth play fundamental roles in the mobilization and ascent dynamics of magmas as well as their flow behavior once erupted on the surface. Here we present a suite of high-temperature vesiculation experiments performed at atmospheric pressure on cores of rhyolitic obsidians with phenocryst contents between 0 and $\sim 10 \mathrm{vol} \%$ and core diameters of up to $12.7 \mathrm{~mm}$. The initial samples are vesicle-free with $\mathrm{H}_{2} \mathrm{O}$ contents $<1 \mathrm{wt} \%$. Sample cores are flash heated to experimental temperatures above their glass transition (Tg) (between 900-1050 ${ }^{\circ} \mathrm{C}$ ) and held at these conditions for timescales of up to $24 \mathrm{~h}$ before quenching.

Permeable gas escape is inhibited in these samples via the formation of a coherent, impermeable molten skin, conserving mass during the experiments. All sample cores increase in volume with time until they reach a maximum value, beyond which diffusion-limited shrinkage due to devolatilization occurs; see also Von Aulock et al. (2017). The volume change over the experimental period is monitored via time-lapse photography in an optical dilatometer. During each experiment the volume of the sample increases as bubbles nucleate and grow. The rate of this volume increase varies systematically with temperature.

Despite the fact that natural heterogeneities (e.g. flow bands or fractures) introduce small and sharply bounded lineaments of reduced vesiculation intensity, bubble nucleation is generally homogenous throughout the greater part of the sample. Bubble size distribution and number density appear to be correlated with sample micro- and nanolite content; whereby lower crystal abundances produce fewer but larger bubbles. Based on the textural evolution of the samples we discuss the implications for flow under magmatic conditions.

Von Aulock, F.W., Kennedy, B.M., Maksimenko, A., Wadsworth, F.B. and Lavallée, Y., 2017. Outgassing from Open and Closed Magma Foams. Frontiers in Earth Science, 5(46). 